The American Journal of Applied sciences

(ISSN - 2689-0992)

VOLUME 04 ISSUE 01 Pages: 12-16

SJIF IMPACT FACTOR (2020: 5. 276) (2021: 5. 634)

OCLC - 1121105553 METADATA IF - 7.987

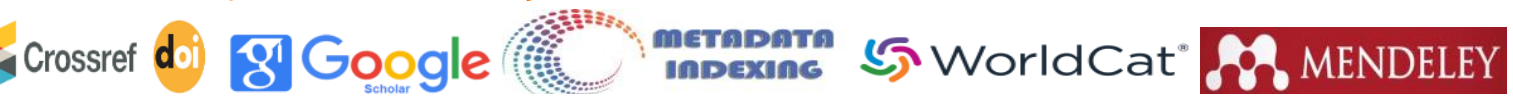

Research Article

\title{
ASSISTANCE IN EMERGENCY SITUATIONS (DROWNING, CONNECTION AND POISONIN)
}

\author{
Submission Date: January 10, 2021, Accepted Date: January 20, 2022, \\ Published Date: January 31, 2022 | \\ Crossref doi: https://doi.org/10.37547/tajas/Volume04lssue01-03 \\ Rumiya Infarovna Sharofutdinova, \\ Lecturers of Bukhara State University, Uzbekistan \\ Zevar Xojievna Tolibova, \\ Lecturers of Bukhara State University, Uzbekistan
}

\section{ABSTRACT}

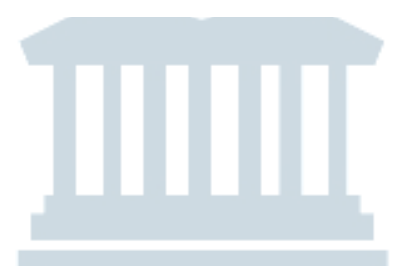

The article discusses the author's views on providing assistance in dangerous situations (drowning, suffocation and poisoning). Secondary drowning can also be accompanied by chest pain or exacerbation, shortness of breath, bruising of the skin and mucous membranes and the development of pulmonary edema, and the appearance of ringing in the breath, excessive foamy sputum, wheezing on the entire surface of the lungs, bronchospasm.

\section{KEYWORDS}

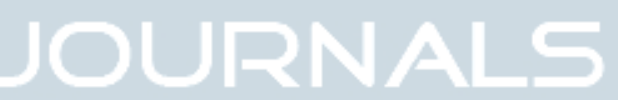

Drowning, respiratory organlfar, closed heart massage, secondary drowning, facial bruising, heart rhythm.

\section{INTRODUCTION}

Drowning is an acute pathological condition that develops as a result of accidental or intentional immersion of a person in a liquid (basal fluid), which complicates or completely stops the exchange of gas with the environment and the entry of air into the respiratory organs. Aspiration of air or other fluid into the airways (congestion) when the anatomical integrity of the respiratory organs is maintained; cessation of pulmonary gas exchange as a result of laryngospasm; may cause cardiac arrest as a result of 
The American Journal of Applied sciences

(ISSN - 2689-0992)

VOLUME 04 ISSUE 01 Pages: 12-16

SJIF IMPACT FACTOR (2020: 5. 276) (2021: 5. 634)

OCLC - 1121105553 METADATA IF - 7.987

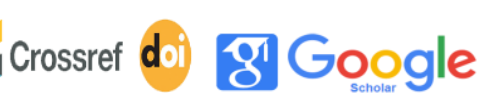

(\%) InDExunc

(5) WorldCat"

Publisher: The USA Journals

psychic or reflex effects (cold shock, shock). The transition of drowning to the terminal state develops in the final stage of cooling in water, in which the disruption of gas exchange and heart activity, as well as muscle movements, leads the body to a state of stupor and loss of consciousness.

\section{MATERIALS AND METHODS}

In true drowning, however, the victim gradually drowns, water slowly enters the lungs, the patient bruises, and often a pink foamy discharge is observed from the mouth and nose. The amount of foam increases relatively when the heart is massaged closed and pressed against the chest. Drowning in a freshwater basin is very different from drowning in seawater. In the freshwater basin, sodium ions are less than in blood plasma, water entering the respiratory tract is quickly absorbed into the blood, which leads to blood thinning, changes in blood erythrocytes. Seawater is rich in sodium ions and its osmotic pressure is higher than that of blood. When seawater enters the alveoli of the lungs, the liquid portion of the blood is directed to the alveoli, causing an acute lung tumor.

In the freshwater basin, sodium ions are less than in blood plasma, water entering the respiratory tract is quickly absorbed into the blood, which leads to blood thinning, changes in blood erythrocytes. Seawater is rich in sodium ions and its osmotic pressure is higher than that of blood. When seawater enters the alveoli of the lungs, the liquid portion of the blood is directed to the alveoli, causing an acute lung tumor.

Conducting resuscitation with people who are familiar with the methods of resuscitation of the ambulance at the scene of the accident and during transportation to the rescue station will further increase the chances of rescue. In the initial period of drowning, help will be aimed at calming, improving blood and blood circulation (anti-shock, heating, wiping, analeptics). During periods of agony and clinical death, complex resuscitation measures are performed to restore independent breathing and heart contractions.

Drownings who do not need the intervention of a medical facility during recovery should also be referred to a hospital. Even short-term fainting during or after drowning should be considered a serious warning as a serious complication of drowning. Acute respiratory distress during transport may recur or begin for the first time (1).

"Secondary drowning" syndrome begins with symptoms such as the appearance or intensification of chest pain, shortness of breath, bruising of the skin and mucous membranes, increased tachycardia. Blood mixed sputum migration is observed. "Secondary drowning" syndrome is sometimes accompanied by abortion, sometimes with progressive lung thickening, and sometimes with the development of progressive alveolar edema. At the initial signs of "secondary drowning" the patient is given artificial ventilation of the lungs, delivered from a concentrated mixture of solutions of sodium oxybutyrate and albumin, saluretics.

Choking occurs when there are obstructions to the passage of air into the lungs. It can be caused by foreign bodies falling into the upper respiratory tract, injury, or excruciating spasms of the vocal cords. It can also occur as a result of the chest being pressed from the outside with house pieces, with earthworks. When first aid is given for shortness of breath, it is necessary to first try to create favorable conditions for the passage of fresh air, and then begin measures to resuscitate the victim.

Suffocation events are also observed for the purpose of suicide. They use slingshots in such suicides. The 
The American Journal of Applied sciences

(ISSN - 2689-0992)

VOLUME 04 ISSUE 01 Pages: 12-16

SJIF IMPACT FACTOR (2020: 5. 276) (2021: 5. 634)

OCLC - 1121105553 METADATA IF - 7.987

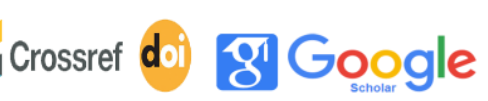

a

5. WorldCat

Publisher: The USA Journals

severity of the condition will depend on the duration of the suffocation and the method of placing the sling. One of the constant signs of suffocation by hanging or slinging is the formation of a leaking or brownish strangulation ejaculate. Blushing of the face, nasopharyngeal hyperemia, swelling and bleeding between the vocal cords. In complete hanging, coma develops with fainting, loss of the pupil's response to light, muscle relaxation, cessation of breathing. In some cases, involuntary defecation and urination are also observed. Death begins in 4-5 minutes. First aid involves quickly lifting and fixing the hanging person, cutting the rope above the knot, and loosening the knot.

In case of snake bites, subcutaneous or intramuscular injection of a toxic substance, a cold compress is applied to the area for $6-8$ hours, $0.3 \mathrm{mg}$ of $0.1 \%$ adrenaline solution, and novocaine is blocked on top of the snake bite.

In case of inhalation poisoning, the poisoned person should be taken to fresh air and inhaled with oxygen.

When the toxic substance is injected directly into the intestine, vagina, bladder, they should be enema, syringe and catheterization.

Induction of diuresis is used using diuretics to remove the toxic substance from the circulatory system.

The main pathological syndromes in acute poisoning. Neurological changes are diverse, resulting from direct toxic effects on the structure of the central and peripheral nervous system, as well as in-toxications due to dysfunction of other organs of the victim (liver and kidneys). The most severe psychoneurological changes include intoxication psychosis, toxic coma, fatigue syndrome. Cardiovascular dysfunction is a toxic shock, which is accompanied by a sudden drop in blood pressure, pale skin, tachycardia, shortness of breath, changes in blood composition (2).

When poisoned with toxins that have a primary effect on the heart, a violation of heart rhythm, its conduction is observed, and collapse develops. Injury of the gastrointestinal tract occurs in the form of acute gastro-enteritis, vomiting, diarrhea, pain in different parts of the abdomen and of varying intensity. Liver damage is accompanied by enlargement and pain of the liver, sclera of the eye, and yellowing of the skin. Usually, short-term nervous changes are also added discomfort, bleeding, bleeding into the skin and mucous membranes. When the kidneys are damaged, often, acute renal failure develops quickly. Toxic substances can accumulate in the gastrointestinal tract, so the stomach and intestines should be washed. First aid in case of poisoning with sleeping pills: the victim is in a coma or in a deep sleep. Inhalation may be intermittent, pale in color or cyanotic (bruising), fever, followed by rash. It is necessary to use activated charcoal or any other sorbents, gastric lavage and send strong laxatives. When intoxicated with alcohol, it should be borne in mind that alcohol has a pronounced psychotropic effect when ingested in large quantities. In the initial period, there is a lack of self-control, a decrease in pain sensation and fainting. First aid includes immediate gastric lavage, airway patency, cardiac medication, and, if possible, oxygen therapy (5).

Gas poisoning. Exhaust gas is formed in the exhaust gases from cars and when homes are heated by stoves. Psychoneurological disorders predominate in acute poisoning, headache, dizziness, thirst, vomiting, fainting, respiratory disorders. First aid, first of all, begins with the immediate removal of the victim from the furnace. It is necessary to ensure the permeability of the bronchi, long-term introduction of air-oxygen 
The American Journal of Applied sciences

(ISSN - 2689-0992)

VOLUME 04 ISSUE 01 Pages: 12-16

SJIF IMPACT FACTOR (2020: 5. 276) (2021: 5. 634)

OCLC - 1121105553 METADATA IF - 7.987

\section{Crossref doi gil Google

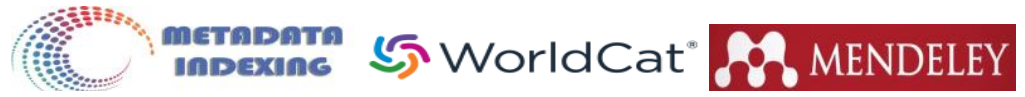

Publisher: The USA Journals

mixture and delivery of cardiovascular drugs. Currently, poisoning by organophosphorus compounds is widespread in industry, agriculture, and at home. This substance affects the nervous system, i.e. fatigue, headache, dizziness, intolerance, respiratory disorders (this condition is associated with relaxation of the respiratory muscles), abdominal pain and diarrhea are observed.

Vinegar poisoning is caused by the essence of vinegar. The clinical course results from local anesthetic effects and general-resorptive effects. Patients complain of severe pain in the throat, vomiting, and delayed breathing. Fluid loss leads to a state of shock. Signs of erythrocyte breakdown - red or brown urine. Treatment is based on gastric lavage, promedol, cardiac medications. The presence of blood in the gastric lavage is an indication that does not preclude further washing (use of alkaline solutions is prohibited). All medicines (antibiotics, serums and vaccines) as well as certain fruit products have allergic properties: eggs, chocolate, honey, strawberries, citrus fruits.

The severity of an allergic reaction is determined by the degree of sensitization. Anaphylactic shock is a set of allergic reactions that can be very severe. Among the persistent symptoms of anaphylactic shock are acute vascular insufficiency, with a sharp drop in blood pressure, paleness or hyperemia of the face, cyanosis, heavy sweating, pulse palpitations. Heart rhythm frequency and accuracy are impaired. Lung tumors may develop and bell-shaped breathing, excessive foamy sputum, wheezing on the entire surface of the lungs, bronchospasm (6).

\section{CONCLUSION}

To conclude, we can say that it is important to provide proper assistance in dangerous situations (drowning, suffocation and poisoning). There is secondary drowning which can be accompanied by chest pain or exacerbation, shortness of breath, bruising of the skin and mucous membranes and the development of pulmonary edema, and the appearance of ringing in the breath, excessive foamy sputum, wheezing on the entire surface of the lungs, bronchospasm. In these cases, the proper application of methods of resuscitation of the ambulance will further increase the chances of rescue.

\section{REFERENCES}

1. Asadullayev A.N. The role of physical education and sports professionals in the organization of a healthy lifestyle in society. Journal of Innovations in Pedagogy and Psychology, 3rd special issue. Tashkent-2020. 31-36.

2. Asadullayev A.N., Ochilova N.R., Jabborova O.G. Healthy lifestyle (Healthy lifestyle) Academicia an international multidisciplinary research journal (ISSN:2249-7137, январь 2021, 1835-1841).

3. Baymuradov R.S., Asadullayev A.N., Baxshullayeva М.В. Роль гигиены физического воспитания в правильном росте и развитии подрастающего поколения.

«Молодой исследователь: вызовы и перспективы» Сборник статей по материалам CCXXVII международной научно-практической конференции № 32 (227) Сентябрь 2021 г. Москва, 158-164 C.

4. Sharofudinova R.I., Asadullayev A.N., Tolibova Z.X. The Factors and Basic Concepts Determining Community Health. Central Asian Journal of Medical and Natural Science (Volume: 02 Issue: 05 Sep-Oct 2021 ISSN: 2660-4159) 376-379. 
The American Journal of Applied sciences

(ISSN - 2689-0992)

VOLUME 04 ISSUE 01 Pages: 12-16

SJIF IMPACT FACTOR (2020: 5. 276) (2021: 5. 634)

OCLC - 1121105553 METADATA IF - 7.987

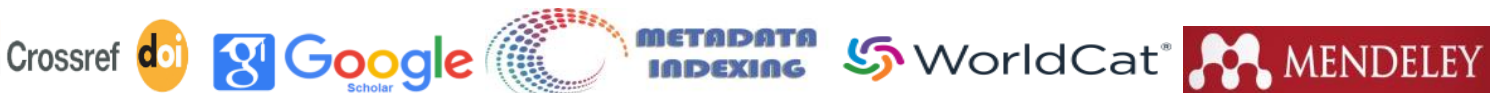

Publisher: The USA Journals

5. Asadullayev A.N. Factors that ensure the necessary level of human health. Bulletin of Khorezm Mamun Academy Khiva-2021. 29-31.

6. Sharofutdinova R.I., Muratova G.S., Tursunboyeva M.T. Принципы формирования концепций экологического образования и воспитания «Биология и интегративная медицина» 2020, 1 (41), 98-105.

7. Sharafutdinova R.I., Muratova G.S., Tursunbayeva M.T. Formation of ecological thinking and educational concepts in students - "New Day in Medicine" 2020, 1 (29), 105-107.

8. Sharafutdinova R.I., Muratova G.S., Jumayeva G.S., Mustafayeva Sh.A. Использование методов совместного обучения в практических занятиях по спортивной медицине- «Современное состояние, проблемы и перспективы медицинского образования» международная учебно-научно-практическая конференция. Бухара 2018.

9. Muratova G.S. Основы психологии общения медицинской сестры. Young scientists' and mentors' non-standart congress, 177-180.2017.

10. Sharafutdinova R.I. Muratova G.S. Role formation of ecological thinking and education in higher education institutions ACADEMICIA: AN INTERNATIONAL MULTIDISCIPLINARY RESEARCH JOURNAL 11 (2), 1400.2021.

11. Sharafutdinova R.I., Muratova G.S. Concepts of ecological thinking and education and their formation in the minds of students Биология $и$ интегративная медицина, 156-161.

12. Muratova G.S., Ochilova G.S., qarshiyeva D.R. The Importance of Water Quality and Quantity in Strengthening the Health and Living Conditions of the Population. CENTRAL ASIAN JOURNAL OF MEDICAL AND NATURAL SCIENCES 2 (5), 399402.2021.
13. Qarshiyeva D.R., Amonov M.R., Ismatova R.A., Ochilova N.R. Разработка нового состава шлихтующей композиции. Международная научная конференция «Инновационные решения инженерно-технологических проблем современного производства». Бухара 2019. 514$517 \mathrm{c}$.

14. Qarshiyeva D.R., Ochilova N.R., Tolibova Z.H. The Role Of Human Healthy And Safe Lifestyle In The Period Of Global Pandemic-Covid 19. The American Journal of Applied sciences, 2020. 